\title{
Novel Constraints on Magmatic Mushes from Kīlauean Olivines
}

\author{
PENNY E. WIESER ${ }^{1}$, MARIE EDMONDS ${ }^{1}$, JOHN \\ MACLENNAN $^{1}$, FRANCES JENNER ${ }^{2}$, BARBARA KUNZ ${ }^{2}$, \\ JOHN WHEELER ${ }^{3}$ \\ ${ }^{1}$ Department of Earth Sciences, University of Cambridge, \\ UK.pew26@cam.ac.uk \\ ${ }^{2}$ School of Environment, Earth and Ecosystem Sciences, The \\ Open University, UK \\ ${ }^{3}$ School of Earth, Ocean and Ecological Sciences, University \\ of Liverpool, UK
}

Magmatic systems are increasingly viewed as mushdominated, with settled crystals forming extensive cumulate piles within the crust before their eruption in unrelated carrier melts. Yet, olivine-hosted melt inclusions are commonly used to interrogate specific eruptions, relying on a close genetic relationship between co-erupting crystals and melts. We assess the validity of this assumption at Killauea Volcano, where geophysical observations indicate that extensive olivine mush piles are located in close proximity to magma storage reservoirs.

Within a single Kīlauean eruption, melt inclusions trapped within primitive olivine crystals exhibit compositional diversity exceeding that in erupted lava compositions since $1790 \mathrm{CE}$. Crucially, there is no obvious eruption-by-eruption correspondence between inclusion compositions and carrier liquids. This feature suggests that erupting liquids scavenge unrelated crystal cargoes from mush piles accumulating diverse melt inclusion populations over timescales $>170$ yrs.

Our investigations of prominent lattice distortions in primitive olivines using Electron Backscatter Diffraction provide a second line of evidence for prolonged mush-zone storage before eruption. Application of piezometers developed for mantle peridotites reveal that distorted crystals have experienced differential stresses of $\sim 3-12 \mathrm{MPa}$, consistent with their derivation from mush piles with thicknesses of $\sim 180-720 \mathrm{~m}$. Simple mass balance constraints reveal that mush piles of this size can accumulate in just a few centuries; consistent with the storage times inferred from melt inclusion trace element diversity. While distorted olivines have been previously attributed to ductile creep within Kîlauea's deep rift zones, we favour their derivation from mush piles at the base of the South Caldera Reservoir (based on their abundance in both summit and rift-zone eruptions, and the absence of adcumulate textures). Overall, while the history of pre-eruptive processes preserved in crystal and melt inclusion records can be obscured by accumulation and storage in long-lived mush piles, careful interrogation of these records provides novel constraints on the geometry and dynamics of magmatic plumbing systems. 